\title{
PROSTHETIC COMPLICATIONS AND PATIENT SATISFACTION WITH MAXILLARY POLYETHER ETHER KETONE HYBRID PROSTHESIS VENEERED WITH ACRYLIC OR COMPOSITE RESIN FOR PATIENTS REHABILITATED BY “ALL ON FOUR" CONCEPT
}

\author{
Dina Bahgat El Talawy* and Samer Mostafa Ali**
}

\begin{abstract}
Purpose: To evaluate prosthetic complications and patient satisfaction with maxillary polyether ether ketone (PEEK) hybrid prosthesis veneered with acrylic or composite resin for individuals restored by "All on four" implants.

Materials and methods: Six patients with edentulous maxilla opposing mandibular implant overdentures had four implants in-between maxillary antrums according to the All on four concept and full arch PEEK fixed restoration veneered with acrylic resin (control group). The study group comprised six patients who had four implants using the All on four protocol and full arch PEEK fixed restoration veneered with composite resin. For both groups, prosthetic complications and patient satisfaction using visual analogue scale were measured after one year.
\end{abstract}

Results: There were no prosthesis fractures, cylinder fracture, abutment fracture, prosthetic screw fractures occurred in both groups. Crown fracture occurred significantly more in the composite group compared to the acrylic group ( $\mathrm{p}=.046$ ). The composite group showed significant higher overall chewing and esthetics compared to the acrylic group. On the other hand, the acrylic group showed significant higher ease of cleaning than the composite group. No difference in mouth comfort and speech between groups was noted.

Conclusion: Both acrylic and composite veneers for full arch PEEK fixed restoration can be used successfully for rehabilitation of patients with maxillary All on four concept as they achieve favorable prosthetic and patient satisfaction out comes. However, composite veneers may be advantageous in term of satisfaction with chewing and esthetics and acrylic veneers may be advantageous in terms of crown fractures and ease of cleaning.

\footnotetext{
* Associate Professor, Department of Removable Prosthodontics, College of Oral and Dental Surgery, Misr University for Science and Technology, Egypt.

** Associate Professor, Department of Removable Prosthodontics, Faculty of Dentistry, October University for Modern Science and Arts (MSA), Egypt.
} 


\section{INTRODUCTION}

Maxillary Implant restoration in edentulism is more challenging than mandibular which may be due to the vertical and horizontal alveolar bone resorption and compromised bone quality, in addition to the maxillary sinus pneumatization in the posterior region, where bone grafting is often indicated ${ }^{1}$. The rehabilitation of atrophic maxillary arch using complete arch fixed implant supported prosthesis (CAFIPs) was reported as a positive line of treatment ${ }^{2}$. The use of 4 or 6 implants to support CAFIPs for edentulous maxilla has recorded high success rates ${ }^{3}$. Maloetal. restored edentulous maxilla with 4 axial and inclined implants immediately loaded by fixed acrylic provisional restoration that was replaced by definitive fixed hybrid prosthesis after complete implant osseointegration following the all on four concept 1,4,5. "The All on Four" implant concept has several merits as reduction of the need of bone grafting and associated patient morbidity, immediate reestablishing of mastication and esthetics by immediate loading of the implants with improved patient psychology ${ }^{6}$, decreasing the number of implants and cantilever lengths. The concept is based on inserting 2 implants just anterior to the maxillary sinuses and inclined $30^{\circ}$ distally and 2 axial implants in the lateral incisor or canine regions ${ }^{1,4,5}$.

The materials used for framework for fixed full arch prosthesis including Nobel metal as gold, base metal alloy as nickel or cobalt chromium, milled materials as titanium and zirconium with its high compatibility, corrosion resistance, and feasibility of computer aided design/computer aided manufacturing ( $\mathrm{CAD} / \mathrm{CAM})$, thus providing more better fit between the framework and the implants ${ }^{7}$. Several drawbacks had been recorded with the conventional metal ceramic full arch fixed restorations as porcelain fractures, screw loosening ${ }^{8}$, warping of the metal framework while firing the veneering porcelain resulting in inaccuracy of fit ${ }^{9}$.
Moreover, this material is hard and has no shock absorption transmitting increased loads to the fixture via the superstructure ${ }^{10}$. The greyish discoloration and possibility of degradation of titanium frameworks results in esthetic complications ${ }^{7}$. Whereas zirconia frameworks cannot be sectioned and reconnected if misfits is found, and had high fractures or chipping of ceramics ${ }^{9}$. On the other hand Polyetheretherketone (PEEK) had been introduced as a thermoplastic polymer which can replace metal framework for fixed full arch restorations owing to its mechanical strength. Moreover, it has a modulus of elasticity similar to the bone, has improved resistance to abrasion and shock absorbing ability $^{10,11}$ resistant to corrosion, biocompatible, integrate with $\mathrm{x}$-ray imaging, radiolucent, has low plaque accumulation and chemical stability ${ }^{12-14}$. PEEK also has a reduced weight which provide lighter prosthesis than metallic restorations thus increasing patient satisfaction and comfort during function ${ }^{9}$. PEEK can be fabricated by either CAD/ CAM or by injection molding ${ }^{9}$. PEEK framework can be veneered with 2 materials; polymethyl methacrylate (PMMA), or composite resin materials. To reduce impact forces, denture weight, and costs, composite resin was used particularly with long complete full arch fixed prosthesis, instead of porcelain. Composite resin has favored appearance and color than acrylic resin ${ }^{7}$.

Computer-aided design/computer-aided manufacturing (CAD/CAM), the biocompatibility and shock absorption has increased use of PEEK $^{15}$. Reviewing the literature, the use of fullarch hybrid PEEK veneered with PMMA acrylic $\operatorname{resin}^{9,15,16}$ or composite resin ${ }^{7}$ prosthesis and supported by 4 implants through the all-on-four concept was reported successfully. However, comparison of clinical performance of both types of veneer materials on PEEK framework was not evaluated. Based on this observation, the aim of the present study was to evaluate prosthetic complications and patient satisfaction with maxillary polyetheretherketone 
hybrid prosthesis veneered with acrylic or composite resin for patients rehabilitated by "All on four" concept. The null hypothesis was that no differences in the 2 veneer materials would be obtained.

\section{MATERIALS AND METHODS}

\section{Patient selection and study design}

This study followed case-control study design. The control group comprised six patients who participated in a previous study ${ }^{17}$ and were evaluated retrospectively and served as historical cohort. Six edentulous participants who worn conventional maxillary dentures and implant supported mandibular dentures were selected for this investigation from patients attending for prosthetic care in Faculty of Dentistry, October University For Modern Science and Arts (MSA) (Study group). The inclusion criteria include; 1) lack of satisfaction of maxillary conventional dentures due to denture instability, 2) atrophy of maxillary ridges with insufficient bone in maxillary posterior ridges. 3) adequate bone dimensions in the anterior maxillary ridges (class III-IV according to Cawood and Howell) ${ }^{18}$ to receive four implants according to the All on four concept (at least $12 \mathrm{~mm}$ in length and 3.8 $\mathrm{mm}$ in diameter). Patients who had these characters were excluded: 1) blood and autoimmune diseases, 2) uncontrolled diabetes mellitus, 3 ) metabolic bone diseases, 4) head or neck radiotherapy, 5) smoking, and 6) Bruxism. The study group was case by case matched to the control group regarding mean age, number of males and females, amount of available bone between the maxillary sinuses, and condition of opposing mandibular arch. Control group comprised 6 participants who had maxillary All on four fixed prosthesis constructed from PEEK framework veneered with acrylic resin. Study group comprised 6 participants who had maxillary All on four fixed prosthesis constructed from PEEK framework veneered with composite resin. Informed consents were obtained from all participants. The study was approved by the faculty ethical committee(ETH 29).

\section{Surgical and prosthetic procedures}

The same surgical procedures that was followed for the control group was replicated for the test group. Gutta perchae markers are fixed to the maxillary denture. Dual scan protocol was done to the denture alone and to the patient while wearing the dentures using cone beam computerized tomography. The data sets of the dual scans were opened with a software (OnDemand). Two anterior implants were placed at lateral incisor or canine areas parallel to each others with slight labial inclination. The posterior 2 implants were distally inclined by $30^{\circ}$ and placed just anterior to the maxillary sinuses. This planning provides short cantilever and increased inter-implant distance and can avoid bone grafting of maxillary sinuses ${ }^{19,20}$. A mucosal born surgical guide with openings over implant sites and anchor pin channels was constructed using laser sintering technique (3D printing technology, In2Guide) for each participant based on the virtual plan (fig 1). The surgery was made according to the flapless protocol by the same oral and maxillofacial surgeon. Four implants (Biohorizon, USA) were installed using the guide and the compatible surgical kit (In2Guide) (fig 2). The guide was fixed in the patient's mouth using interocclusal registration and fixed to the bone using anchor pins.

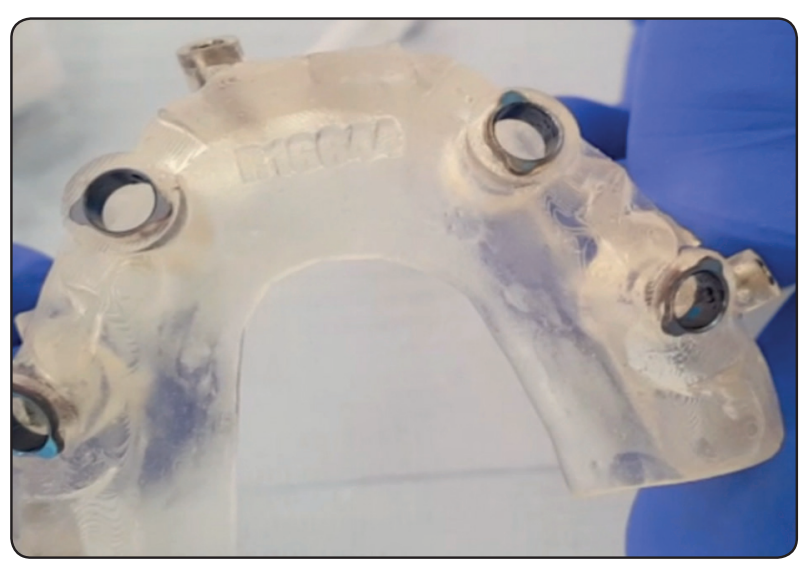

Fig. (1) Stereolithographic guide constructed by laser sintering 
The allowed torque during implant insertion was not less than $35 \mathrm{Ncm}$ to allow immediate loading ${ }^{21}$. Under-preparation of the implant osteotomy was made (by omitting the final drill) if needed in case of soft bone density to guarantee a final torque of $\geq$ $40 \mathrm{Ncm}$ before the final implant seating. $17^{\circ}$ multiunit abutments (Biohorizon, USA) were screwed to the anterior implants and $30^{\circ}$ abutments were connected to posterior implants (fig 2).

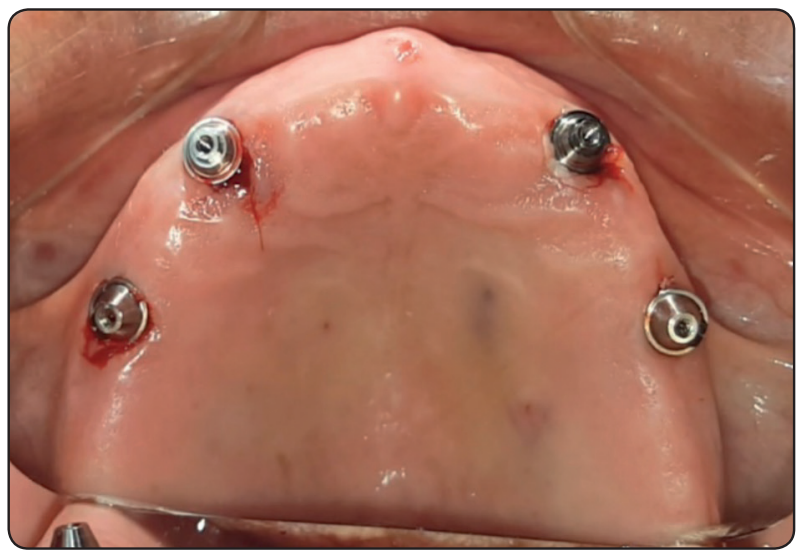

Fig. (2) Connection of multiunit abutments to the implants

Temporary metal caps were screwed to the multiunit abutments. Implants were immediately loaded by existing maxillary dentures after removal of the labial, buccal flanges and the palate ${ }^{17}$. Also the second molars were removed ${ }^{22}$. The metal caps were attached to the denture using self-cure acrylic resin. Occlusion was relieved to avoid loading on the inclined posterior implants ${ }^{17}$. Postoperative medications include Antibiotics twice for 6 days, Corticosteroids to reduce postoperative edema and inflammation and analgesics for the first 5 days.

After osseointegration, open tray abutment level impression was started. The abutment level long transfer copings were splinted with Duralay resin and open tray impression was completed using rubber base material (Zhermack ${ }^{\circledR}$, Italy). Abutment analogues were connected and the impression was poured. Titanium caps were screwed to the abutment analogues. Jaw relation was completed.
The cast was scanned using a CAD/CAM device (Amann Girrbach, Austria), then a fixed prosthesis was designed and milled in Polyether ether Ketone (PEEK, BioHPP) discs (Bredent, Germany). The milled frame was fixed to the metal caps using resin cement and the prosthesis was tried in patient mouth for passivity (fig 3). The occlusal scheme was bilateral balanced occlusion to enhance the stability of mandibular implant overdentures.

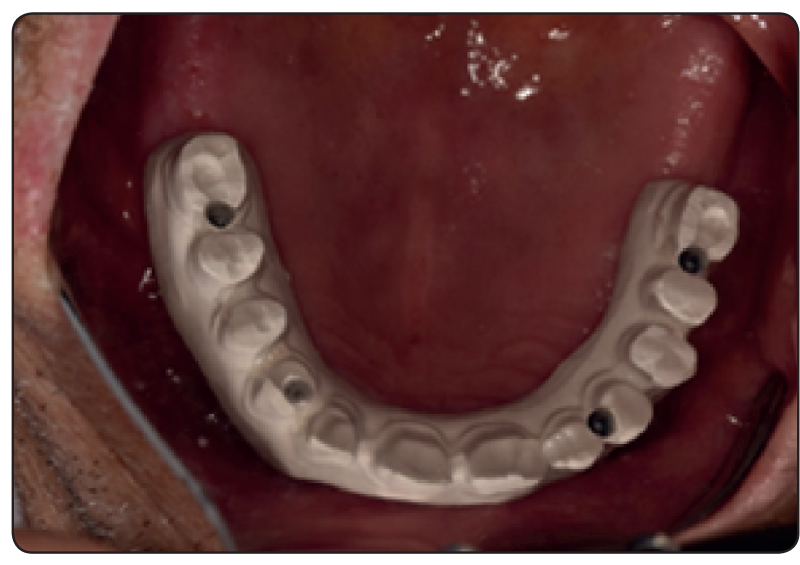

Fig (3) Try in of the milled PEEK framework in patient mouth

For both groups, The BioHPP framework was sandblasted by using $110 \mu$ aluminum oxide (Al2O3) at $0.25 \mathrm{MPa}$ for 30 seconds at a distance of $1 \mathrm{~cm}$, and then cleaned with water in an ultrasonic bath for 10 minutes. For control group (Acrylic resin), acrylic resin teeth (Acrostone; Acrostone Dental Manufacturer, Egypt) were used. Visio. Link adhesive was applied on the surface of the framework according to manufacturer's instructions. The frame was flasked and acrylic resin (Acrostone; Acrostone Dental Manufacturer, Egypt) was packed over the frame and polymerized according to the manufacturer's instructions, finished and polished (Fig 4). For study group (composite resin), Visio. lign (Bredent GmbH, Senden, Germany) composite teeth and pink Visio.lign composite that restore lost gingival tissue was used. Bonding agent; Visio. Link was applied on the surface of the framework according to manufacturer's instructions (fig 5). The maxillary prostheses were inserted. 


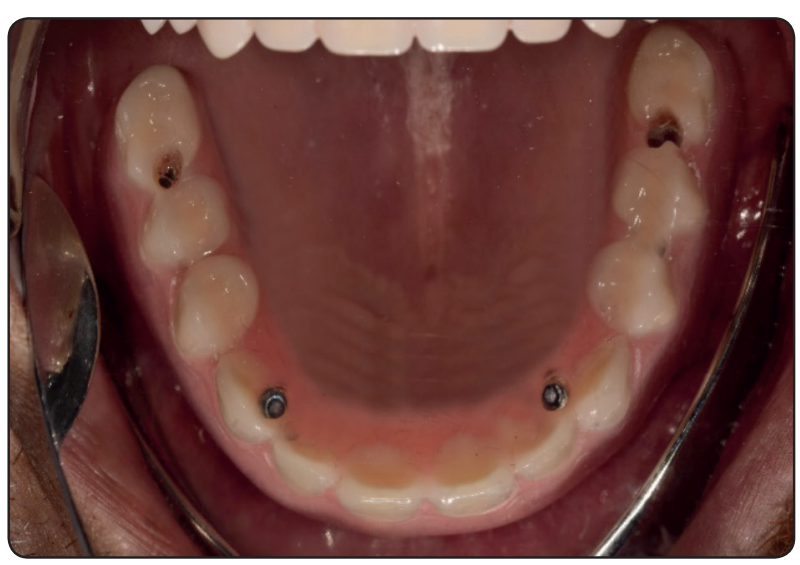

Fig. (4) Control group (PEEK veneered with acrylic resin)

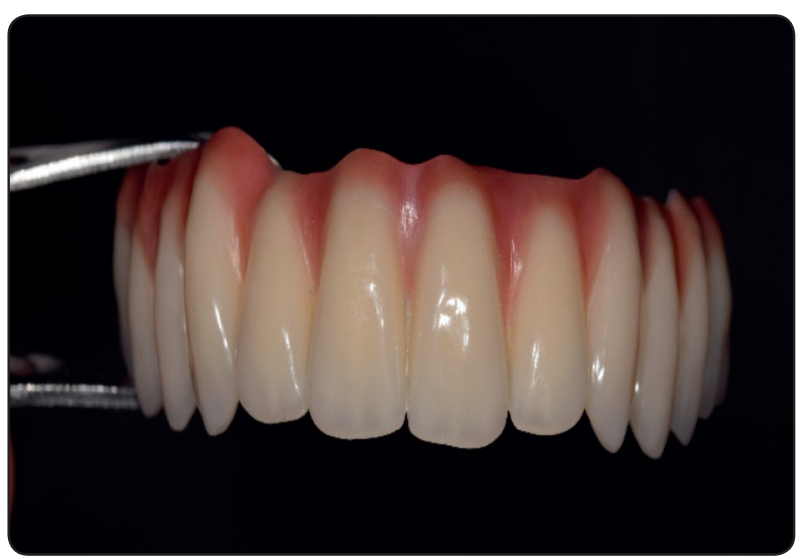

Fig. (5) Study group (PEEK veneered with composite)

\section{Evaluation of Prosthetic complications}

Prosthetic complications include Prostheses fracture, crown fracture, cylinder fracture, artificial gingiva fracture, abutment fracture, abutment screw loosening, prosthetic screw fracture, and prosthetic screw loosening ${ }^{23}$. Complications were measured after one year from prosthesis insertion.

\section{Evaluation of patient satisfaction}

The patient satisfaction score was marked on a visual analogue scale ranging between 0-10 (poor to excellent) and include: "in-mouth comfort" which is comfort in function, and "overall chewing feeling", which is feeling during food mastication in daily food intake (ability to chew any type of food $)^{16}$. Moreover, satisfaction with appearance, speech, ease of cleaning were measured ${ }^{24}$.Prosthetic complications and patient satisfaction data for control group was collected retrospectively from patient records after one year. The data of the test group was collected prospectively after one year.

\section{Statistical analysis}

The descriptive statistics of both prosthetic complications for both groups were calculated in terms of frequency and percentages. To test the difference in complications between groups, the Chi-square test was used. Patient satisfaction scores were described in median (min-max) and compared between groups using Mann Whitney test. P-values $<0.05$ were considered to be significant.

\section{RESULTS}

Prosthetic complications of composite and acrylic groups were presented in table 1. There were no prosthesis fractures (on patient level) and no cylinder, abutment fracture, prosthetic screw fractures (on implant level) occurred in both groups and the survival rate of the prosthesis was $100 \%$ in both groups. Artificial acrylic crown (veneer) fractures occurred in 3 Prostheses (50\%) in the composite group and no crown fractures occurred in the acrylic group. The composite group showed significantly higher crown fracture than the acrylic group $(\mathrm{p}=.046)$. Teeth wear occurred in 1 Prosthesis (16\%) in the composite group and 3 prostheses $(50 \%)$ in the acrylic group. There was no difference in teeth wear between groups $(\mathrm{p}=.22)$. One gingival acrylic fracture (16\%) occurred in the composite group and no fractures occurred in the acrylic group. No significant difference in gingival acrylic fractures between groups was noted $(\mathrm{p}=.29)$. Abutment screw loosening occurred in 5 implants $(20.8 \%)$ belonged to the composite group and in 4 implants (16.6\%) in the acrylic group. No significant difference in abutment screw loosening between groups was noted $(\mathrm{p}=.71)$. Prosthetic screw 
loosening occurred in 8 implants $(33 \%)$ belonged to the composite group and $6(25 \%)$ prosthetic screw loosening occurred in the acrylic group. No significant difference in prosthetic screw loosening between groups was noted $(\mathrm{p}=.52)$.

The results of VAS of both groups are presented in table 2. The median overall chewing scores of composite group was significantly higher than median scores of acrylic resin group $(p=.002)$. No significant difference in the median scores of in mouth comfort between groups was noted $(\mathrm{p}=.357)$. The median scores of satisfaction with esthetics in composite group was significantly higher than acrylic group $(p<.001)$. The median scores of satisfaction with cleaning of the prosthesis in the acrylic group was significantly higher than median scores of composite group. No significant difference in the median scores of satisfaction with speech was observed between groups $(\mathrm{p}=.258)$.

TABLE (1) Prosthetic complications of Composite and acrylic groups

\begin{tabular}{|c|c|c|c|c|c|}
\hline \multirow{3}{*}{ Prosthesis fracture } & \multicolumn{2}{|c|}{ Test group (Composite) } & \multicolumn{2}{|c|}{ Control group (Acrylic) } & P-value \\
\hline & \multicolumn{5}{|c|}{ On patient level } \\
\hline & 0 & $0 \%$ & 0 & $0 \%$ & 1.00 \\
\hline Crown (veneer) fracture & 3 & $50 \%$ & 0 & $0 \%$ & $.046^{*}$ \\
\hline Teeth wear & 1 & $16 \%$ & 3 & $50 \%$ & .22 \\
\hline \multirow[t]{2}{*}{ Gingiva fracture } & 1 & $16 \%$ & 0 & $0 \%$ & .29 \\
\hline & \multicolumn{5}{|c|}{ On implant level } \\
\hline Cylinder fracture & 0 & $0 \%$ & 0 & $0 \%$ & 1.00 \\
\hline Abutment fracture & 0 & $0 \%$ & 0 & $0 \%$ & 1.00 \\
\hline Abutment screw loosening & 5 & $20.8 \%$ & 4 & $16.6 \%$ & .71 \\
\hline Prosthetic screw fracture & 0 & $0 \%$ & 0 & $0 \%$ & 1.00 \\
\hline Prosthetic screw loosening & 8 & $33.3 \%$ & 6 & $25 \%$ & .52 \\
\hline
\end{tabular}

*p is significant at $5 \%$

TABLE (2) Patient satisfaction on visual analogue scale (VAS) of Composite and acrylic groups

\begin{tabular}{|l|c|c|c|}
\hline & $\begin{array}{c}\text { Composite } \\
\text { M (min-max) }\end{array}$ & $\begin{array}{c}\text { Acrylic } \\
\text { M (min-max) }\end{array}$ & Mann Whitney test \\
\hline Overall chewing & $85(52-73)$ & $77(50-70)$ & $.002^{*}$ \\
\hline In mouth comfort & $88(68-95)$ & $85(69-92)$ & .357 \\
\hline Aesthetics & $92(99-83)$ & $78(70-90)$ & $<.001^{*}$ \\
\hline Cleaning of prosthesis & $76(69-84)$ & $88(80-92)$ & $.004^{*}$ \\
\hline Speech & $85(81-95)$ & $87(80-94)$ & .258 \\
\hline
\end{tabular}

M: median, min: minimum, max: maximum. ${ }^{* P}$ value is significant at $5 \%$ level 


\section{DISCUSSION}

There were no prosthesis fractures, cylinder fracture, abutment fracture, prosthetic screw fractures occurred in both groups and the survival rate of the prosthesis was $100 \%$. This may be due to these complications are usually associated with porcelain fused to metal restorations and increased bite forces especially if natural opposing occlusion is present. In this study the use of acrylic or composite resin teeth produce a cushion effect to the applied load compared to the metal-ceramic prosthesis and the opposing occlusion contain acrylic resin teeth of the overdentures which has a dampening effect. Another explanation of reduced maximum bite force is the old patients ${ }^{25}$ included in the study who had a reduced strength of the masticatory muscles compared to young patients and exclusion of patients with bruxism ${ }^{26}$. Furthermore, the elastic properties of the PEEK framework which reduce masticatory forces, and protect the abutment and prosthetic screws from damage ${ }^{27}$. This is an advantage compared to rigid metallic frames. In line with our finding, Nobre et al. ${ }^{15}$ noted that prosthetic survival was influenced by the state of the opposing jaw and prosthetic failure occluded in patients rehabilitated by All on four concept in the upper and lower jaw with bruxism that caused a framework fracture, which suggest occlusal overload.

PEEK had low surface energy thus a chemical surface treatment of the PEEK is needed to achieve sufficient bond strength to a veneering material. This is a challenge in the construction of $\mathrm{PEEK}^{28}$. The most important and interesting finding of this study is the increased crown (or veneer) fracture in the composite group compared to the acrylic group. A similar finding was obtained in another invitro study $^{29}$. This may be due to the initial shear bond strength of polymethyl methacrylate (PMMA) to PEEK is significantly higher than that of composite resin to PEEK $^{29}$. The use of MMA monomers may contribute to increased bond strength between
PEEK and acrylic resins after air-abrasion as it creates substantial chemical bonding to PEEK $^{30}$. Furthermore, post-polymerization of the adhesive system and the veneering acrylic resin (caused by elevation of temperature during PMMA heat curing process) produce higher bond strength of PMMA to $\mathrm{PEEK}^{31}$. Another explanation is the fact that composite veneers has to be bonded twice, one bonding is used for adhesion of composite teeth to the pink composite resin of the gingiva, and the other bond process is for adhesion of pink composite resin of the gingiva to the PEEK frame. This may weaken the adhesion of composite teeth and cause composite teeth fracture or separation from the pink composite resin. On the other hand, acrylic resin is bonded in one occasion only for adhesion of the pink acrylic resin of the gingiva to the PEEK frame as acrylic teeth is chemically bonded to the pink acrylic resin of the gingiva during processing. This finding was in line with the results of another study $^{32}$ in which the authors observed that screwretained PEEK crowns veneered with composite for maxillary central incisor showed significantly lower fracture strength than those on titanium temporary abutments. The authors attributed this complication to the cohesive fractures of the composite resin crowns, and recommended that adhesion between the PEEK material and the composite resin could be a topic for future studies.

In contrast, Wachtel et al. ${ }^{27}$ reported that single screw-retained PEEK implant crowns veneered with composite have no damage to the veneer or the PEEK framework during masticatory simulation and concluded that PEEK implant crowns considered definitive restorations ${ }^{27}$. Also, Nobre et al. ${ }^{15}$ reported more veneer adhesion problems (acrylic resin avulsion from PEEK infrastructure) for patients rehabilitated with full-arch fixed hybrid PEEK-acrylic resin prosthesis used in conjunction with the All on four concept. In this study we reported no acrylic resin fracture from the PEEK frame. The difference in the results may be due to 
in the study of Nobre et al. ${ }^{15}$, the majority of the Prostheses contained more than one cantilevered teeth rendering technical complications (veneer adhesion issues) more common due to flexing of the PEEK framework distal cantilever. However, in this study no cantilevers or maximum one tooth cantilever was used. Another explanation is the use of a primer suggested by the manufacture with higher tensile bond strength, supported by the results of previous investigations ${ }^{31}$. Moreover, the PEEK frame was increased in thickness by providing PEEK projections below the teeth. This may reduce PEEK frame flexion and consequently reduce fracture of acrylic teeth ${ }^{16}$. Furthermore, in this study we provided a rough finish, and vertical and horizontal thread in the remaining PEEK infrastructure that increased mechanical retention of the acrylic resin in the PEEK infrastructure. Also, no fixed restoration was present in the opposing arch in this study, while in the study of Nobre et al. ${ }^{15}$ patients with All on four fixed restoration in opposing jaw and patients with bruxism were included.

Abutment screw loosening, teeth wear and prosthetic screw loosening occurred in both groups were noted for anterior implant abutments more than posterior implants. This may be due to increased occlusal load on the anterior implants by presence of 2 implant supported overdentures in the mandible. This may encourage the patients to incise anteriorly with increased bite force ${ }^{33}$ creating a similar biomechanical situation to the distal extension removable partial denture ${ }^{34}$. This caused increased forces to the maxillary anterior region ${ }^{35}$. The increased bite forces on the anterior teeth of the prosthesis may induce abutment screw loosening, teeth wear and prosthetic screw loosening that usually occurred on the anterior teeth. The occurrence of screw loosening was reported previously for both PEEK veneered with composite $^{32}$, or PEEK veneered with acrylic resin ${ }^{15}$ prosthesis. Both composite and acrylic resin have reduced impact strength and shock absorbing ability. Therefore, no difference abutment screw loosening, and prosthetic screw loosening between groups was noted. The fact that composite or acrylic pink gingiva were adhered to the PEEK using the same adhesive could be responsible for the lack of difference in gingival fracture between groups.

The increased patient satisfaction and oral health related quality of life following rehabilitation with All on four fixed hybrid restoration was reported in the literature ${ }^{36,37}$. The composite group showed significant higher overall chewing and esthetics compared to the acrylic group. The increased satisfaction with chewing with composite resin prosthesis may be retributed to the increased surface hardness of the composite resin compared to the acrylic $\operatorname{resin}^{38}$ which increase chewing efficiency. The increased satisfaction with esthetics with composite restoration compared to acrylic restoration may be due to composite resin anterior teeth usually veneered on the PEEK frame. There are several color shades provided by the manufacture to select the appropriate color of the teeth and pink gingiva accurately. Conversely, the acrylic resin colors usually limited to only 3 colors (light, medium, dark shades). Moreover, to obtain adequate color with acrylic prosthesis, increased thickness of the acrylic resin should be made to eliminate the white shadow of the PEEK frame. This will increase the bulkiness of the prosthesis and may cause lip stretching and patient discomfort. Another method to enhance the esthetic of the acrylic resin is to use opaquer on the PEEK frame before packing. The opaquer was not used in this study as it will affect bond strength of the acrylic resin to the PEEK frame.

On the other hand, the acrylic group showed significant higher ease of cleaning than the composite group. This may be due to artificial acrylic resin teeth had significantly reduced color changes and more color stable that than did the veneering composite materials. ${ }^{39}$ The change in color of acrylic resin is usually easy to be cleaned by 
brushing since the surface of acrylic resin is highly finished and polished. In contrast, bonding between composite veneers and pink composite gingiva may produce leakage with time and food stagnation that was difficult to be cleaned without removing the prosthesis and sending it to the lab for polishing. The increased patient satisfaction and comfort with PEEK/acrylic resin prosthesis for maxillary All on four full arch fixed prosthesis was reported in another study ${ }^{15}$ in which the authors reported 90\% satisfaction rate for the patients' subjective evaluation in both "in-mouth comfort" and "overall chewing feeling”.

\section{CONCLUSION}

Within the limitations of this study, both acrylic and composite veneers for full arch PEEK fixed restoration can be used successfully for rehabilitation of patients with maxillary All on four concept as they achieve favorable prosthetic and patient satisfaction out comes. However, composite veneers may be advantageous in term of satisfaction with chewing and esthetics and acrylic veneers may be advantageous in terms of crown fractures and ease of cleaning.

\section{REFERENCES}

1. Malo P, de Araujo Nobre M, Lopes A, Francischone C, Rigolizzo M. "All-on-4" immediate-function concept for completely edentulous maxillae: a clinical report on the medium (3 years) and long-term (5 years) outcomes. Clin Implant Dent Relat Res 2012; 14 Suppl 1: e139-150.

2. Castillo-Oyague R, Suarez-Garcia MJ, Perea C, Rio JD, Lynch CD, Gonzalo E, Torres-Lagares D, Preciado A. Validation of a new, specific, complete, and short OHRQoL scale (QoLFAST-10) for wearers of implant overdentures and fixed-detachable hybrid prothesis. J Dent 2016; 49: 22-32.

3. Agliardi EL, Pozzi A, Stappert CF, Benzi R, Romeo $\mathrm{D}$, Gherlone E. Immediate fixed rehabilitation of the edentulous maxilla: a prospective clinical and radiological study after 3 years of loading. Clin Implant Dent Relat Res 2014; 16: 292-302.
4. Malo P, Nobre M, Lopes A. The rehabilitation of completely edentulous maxillae with different degrees of resorption with four or more immediately loaded implants: a 5-year retrospective study and a new classification. Eur J Oral Implantol 2011; 4: 227-243.

5. Malo P, Rangert B, Nobre M. All-on-4 immediate-function concept with Branemark System implants for completely edentulous maxillae: a 1-year retrospective clinical study. Clin Implant Dent Relat Res 2005; 7 Suppl 1: S88-94.

6. Meloni SM, De Riu G, Pisano M, Cattina G, Tullio A. Implant treatment software planning and guided flapless surgery with immediate provisional prosthesis delivery in the fully edentulous maxilla. A retrospective analysis of 15 consecutively treated patients. Eur J Oral Implantol 2010; 3: 245-251.

7. Jin HY, Teng MH, Wang ZJ, Li X, Liang JY, Wang WX, Jiang S, Zhao BD. Comparative evaluation of BioHPP and titanium as a framework veneered with composite resin for implant-supported fixed dental prothesis. J Prosthet Dent 2019; 122: 383-388.

8. Sailer I, Philipp A, Zembic A, Pjetursson BE, Hammerle $\mathrm{CH}$, Zwahlen M. A systematic review of the performance of ceramic and metal implant abutments supporting fixed implant reconstructions. Clin Oral Implants Res 2009; 20 Suppl 4: 4-31.

9. Zoidis P. The all-on-4 modified polyetheretherketone treatment approach: A clinical report. J Prosthet Dent 2018; 119: 516-521.

10. Conserva E, Menini M, Tealdo T, Bevilacqua M, Ravera G, Pera F, Pera P. The use of a masticatory robot to analyze the shock absorption capacity of different restorative materials for prosthetic implants: a preliminary report. Int J Prosthodont 2009; 22: 53-55.

11. Rosentritt M, Schneider-Feyrer S, Behr M, Preis V. In Vitro Shock Absorption Tests on Implant-Supported Crowns: Influence of Crown Materials and Luting Agents. Int J Oral Maxillofac Implants 2018; 33: 116-122.

12. Hahnel S, Wieser A, Lang R, Rosentritt M. Biofilm formation on the surface of modern implant abutment materials. Clin Oral Implants Res 2015; 26: 1297-1301.

13. Wang H, Xu M, Zhang W, Kwok DT, Jiang J, Wu Z, Chu PK. Mechanical and biological characteristics of diamond-like carbon coated poly aryl-ether-ether-ketone. Biomaterials 2010; 31: 8181-8187. 
14. Zoidis P, Papathanasiou I, Polyzois G. The Use of a Modified Poly-Ether-Ether-Ketone (PEEK) as an Alternative Framework Material for Removable Dental Prothesis. A Clinical Report. J Prosthodont 2016; 25: 580-584.

15. de Araujo Nobre M, Moura Guedes C, Almeida R, Silva A, Sereno N. Hybrid Polyetheretherketone (PEEK)-Acrylic Resin Prothesis and the All-on-4 Concept: A Full-Arch Implant-Supported Fixed Solution with 3 Years of FollowUp. J Clin Med 2020; 9.

16. Malo P, de Araujo Nobre M, Moura Guedes C, Almeida R, Silva A, Sereno N, Legatheaux J. Short-term report of an ongoing prospective cohort study evaluating the outcome of full-arch implant-supported fixed hybrid polyetheretherketone-acrylic resin prothesis and the All-on-Four concept. Clin Implant Dent Relat Res 2018; 20: 692-702.

17. Ali SM, D.B. ET. Clinical and radiographic outcomes of polyetheretherketone (PEEK) hybrid prosthesis used for "All on four" rehabilitation of edentulous maxilla. A shortterm case series study. Egyptian Dental Journal 2019; 65: 3699-3712.

18. Cawood JI, Howell RA. A classification of the edentulous jaws. Int J Oral Maxillofac Surg 1988; 17: 232-236.

19. Malo Bo R, Nobre M. Concept with Brlaanemark System Itextregistered Implants for Completely Edentulous Mandibles : A Retrospective Clinical Study. Implant dentistry 2003: 2-9.

20. Malo P, Rangert B, Nobre M. "All-on-Four" immediatefunction concept with Branemark System implants for completely edentulous mandibles: a retrospective clinical study. Clin Implant Dent Relat Res 2003; 5 Suppl 1: 2-9.

21. Sannino G, Bollero P, Barlattani A, Gherlone E. A Retrospective 2-Year Clinical Study of Immediate Prosthetic Rehabilitation of Edentulous Jaws with Four Implants and Prefabricated Bars. J Prosthodont 2017; 26: 387-394.

22. Galindo DF, Butura CC. Immediately loaded mandibular fixed implant prothesis using the all-on-four protocol: a report of 183 consecutively treated patients with 1 year of function in definitive prothesis. The International journal of oral \& maxillofacial implants 2012; 27: 628-633.

23. Maló P, de Araújo Nobre M, Lopes A, Ferro A, Botto J. The All-on-4 treatment concept for the rehabilitation of the completely edentulous mandible: A longitudinal study with 10 to 18 years of follow-up. Clin Implant Dent Relat Res 2019.
24. ELsyad MA, Elgamal M, Mohammed Askar O, Youssef Al-Tonbary G. Patient satisfaction and oral health-related quality of life (OHRQoL) of conventional denture, fixed prosthesis and milled bar overdenture for All-on-4 implant rehabilitation. A crossover study. Clin Oral Implants Res 2019.

25. ELsyad MA, Ibrahim AE, Nawar NHH, Belal TM. Electromyographic Connectivity of Masseter Muscle with Different Retentive Attachments for Implant Overdentures in Patients with Atrophied Mandibular Ridges: A Crossover Study. Int J Oral Maxillofac Implants 2019; 34: 12131222 .

26. Tashkandi EA, Lang BR, Edge MJ. Analysis of strain at selected bone sites of a cantilevered implant-supported prosthesis. J Prosthet Dent 1996; 76: 158-164.

27. Wachtel A, Zimmermann T, Sutel M, Adali U, AbouEmara M, Muller WD, Muhlemann S, Schwitalla AD. Bacterial leakage and bending moments of screw-retained, composite-veneered PEEK implant crowns. J Mech Behav Biomed Mater 2019; 91: 32-37.

28. Schwitalla AD, Botel F, Zimmermann T, Sutel M, Muller WD. The impact of argon/oxygen low-pressure plasma on shear bond strength between a veneering composite and different PEEK materials. Dent Mater 2017; 33: 990-994.

29. Eltombakshy MA, M.S.. E, D.M. A. Shear Bond Strength of different resin-based materials Processed on Poly-etherether ketone frameworks (IN VITRO STUDY). Alexandria Dental Journal 2019; 44: 93-98.

30. Kern M, Lehmann F. Influence of surface conditioning on bonding to polyetheretherketon (PEEK). Dent Mater 2012; 28: $1280-1283$.

31. Stawarczyk B, Keul C, Beuer F, Roos M, Schmidlin PR. Tensile bond strength of veneering resins to PEEK: impact of different adhesives. Dent Mater J 2013; 32: 441-448.

32. Santing HJ, Meijer HJ, Raghoebar GM, Ozcan M. Fracture strength and failure mode of maxillary implant-supported provisional single crowns: a comparison of composite resin crowns fabricated directly over PEEK abutments and solid titanium abutments. Clin Implant Dent Relat Res 2012; 14: 882-889.

33. Thiel CP, Evans DB, Burnett RR. Combination syndrome associated with a mandibular implant-supported overdenture: a clinical report. J Prosthet Dent 1996; 75: 107-113. 
34. Barber HD, Scott RF, Maxson BB, Fonseca RJ. Evaluation of anterior maxillary alveolar ridge resorption when opposed by the transmandibular implant. J Oral Maxillofac Surg 1990; 48: 1283-1287.

35. Alrajhi MS, Askar O, Habib AA, Elsyad MA. Maxillary Bone Resorption with Conventional Dentures and Four-Implant-Supported Fixed Prosthesis Opposed by Distal-Extension Partial Dentures: A Preliminary 5-year Retrospective Study. Int J Oral Maxillofac Implants 2020; 35: 816-823.

36. MA EL, Elgamal M, Mohammed Askar O, Youssef AlTonbary G. Patient satisfaction and oral health-related quality of life (OHRQoL) of conventional denture, fixed prosthesis and milled bar overdenture for All-on-4 implant rehabilitation. A crossover study. Clin Oral Implants Res 2019; 30: 1107-1117.

37. ElSyad MA, Alameldeen HE, Elsaih EA. Four-implantsupported fixed prosthesis and milled bar overdentures for rehabilitation of the edentulous mandible: A 1-year randomized controlled clinical and radiographic study. Int J Oral Maxillofac Implants 2019; 34: 1493-1503.

38. Suwannaroop P, Chaijareenont P, Koottathape N, Takahashi $\mathrm{H}$, Arksornnukit $\mathrm{M}$. In vitro wear resistance, hardness and elastic modulus of artificial denture teeth. Dent Mater J 2011; 30: 461-468.

39. Rosentritt M, Esch J, Behr M, Leibrock A, Handel G. In vivo color stability of resin composite veneers and acrylic resin teeth in removable partial dentures. Quintessence Int 1998; 29: 517-522. 